\title{
A NOTE ON $q$-MKZ OPERATORS USING GENERATING FUNCTIONS
}

\author{
HONEY SHARMA AND RAMAPATI MAURYA*
}

Abstract. This paper is based on new generalization of $q$-analogue of the MKZ type operators using generating functions. We study approximation properties of the proposed operator using Korovkin type theorem. Further, we estimate the rate of convergence of these operators by using the modulus of continuity. In the last, we introduce and establish the uniform convergence of $2 D$-generalization of the $q$-MKZ operators using generating functions.

Mathematics subject classification (2010): 41A10, 41A25, 41A36. tion.

Keywords and phrases: $q$-calculus, rate of convergence, modulus of continuity, Lipschitz class func-

\section{REFERENCES}

[1] A. Aral, V. Gupta And R. P. Agarwal, Applications of q-Calculus in Operator Theory, Springer, New York, 2013.

[2] A. Altin, O. DoĞRU And F. TAŞDElen, The generalization of Meyer-König and Zeller operators by generating functions, J. Math. Anal. Appl., 312, (2005), 181-194.

[3] E. W. Cheney And A. Sharma, Bernstein power series, Canad. J. Math., 16, (1964), 241-252.

[4] I. BÜYÜKYAZIKI AND H. SHARMA, Approximation properties of two dimensional q-BernsteinChlodowsky-Durrmeyer operators, Num. Func. Analy. and Opt., 33, 12 (2012), 1351-1371.

[5] O. DŏgRu And O. Duman, Statistical approximation of Meyer-König and Zeller operators based on q-integers, Publ. Math. Debrecen, 68, 1-2 (2006), 199-214.

[6] T. TRIF, Meyer-König and Zeller operators based on the q-integers, Rev. Anal. Numer. Theor. Approx., 29, 2 (2000), 221-229.

[7] V. I. VOLKOV, On concvergence of sequences of linear positive operators in the space of two variables, Dokl. Akad. Nauk., SSSR (N. S.), 115, (1957), 17-19.

[8] W. MeYer-König AND K. ZEller, Bernsteinsche Potenzreihen, Studia Math., 19, (1960), 89-94. 